\title{
ASPECTOS DA TEMPORALIDADE EM "O DELFIM"
}

\section{Juril do Nascimento Campelo}

Considerando que a narrativa envolve sempre problemas de tempo e que este implica em um processamento peculiar da matéria narrada, torna-se imperioso analisar seus múltiplos aspectos em 0 Delfim. A determinação da temporalidade só será possível se reconhecermos que há três tempos em questão( ${ }^{1}$ ), o tempo da diegese ou da ação, o tempo do discurso ou da narrativa e o tempo da instância narrativa, aquele que segundo Genette é o tempo em que se situa e processa a própria escrita do romance.

O tempo da diegese ou da ação supōe uma cronologia que é a própria ordem natural do $s$ fatos. Em 0 Delfim ele representa a primeira ida do narrador à Gafeira no outono ante:ior, conhecimento dos personagens e fatos naquela ocasião, a ocorrência da tragédia na casa da Lagoa durante a ausência do narrador, a volta do narrador à Gafeira, durante a ausência do narrador, a volta do narrador à Gafeira, no outono atual, conhecimento da tragédia, tentativa de elucidá-la. Estas seriam as etapas cronológicas da diegese. Os limites temporais, como bem pudemos notar, são os dois outonos, o que acrecenta um significado cósmico à narrativa.

O tempo do discurso, no presente romance preocupa-se, sobretudo, com a subversão do tempo da ação. É ele o responsável pelo caráter fragmentário e cambiante da narrativa. As anacronias, que se constituem nos desencontros entre as duas ordens temporais, a da ação, e a do discurso, vão predominar de maneira ext:aordinária neste romance que, desde o seu inicio, que se verifica, in ultima re, lança a anacronia como recurso básico de desenvolvimento. Assim, pelo tempo do discurso, temos, primeiro, o narrador instalado na pensão dos caçadores na Gafeira, no tempo presente, a evocação de a!gumas cenas do ano anterior, o conhecimento das mortes na casa da Lagoa, e a partir daí a tentativa desesperáda do narrador de recons-

Este estuda censtitui um capitulo da tese de coneurso a D-cência Livre, intitulada "O Del. fim: o maneirismo comn expressīo da romance contemorśneo", aproveda com nota 9,8 pela seguinte banca examinadora: Prof.a Dra. Maria das Dres Wouk. Pref.a Dra. Miguelina Soifer, Prof. Dr. Oscar Lermenn, Prof. Dr. Massaud Moisés, Prof. Dr. Anionio Salics Fiiho.

1 Usaremos o ordenaçăo proposta por Vitor Manuel de Aguiar e Silva. A estru. tura do Romance. Coimbra, Livraria Almedina, 1974. p. 51 e ss. 
truir o passado para compreender a causa das mortes, tentativa esta pontilhada de analepses e prolepses, até a página final do romance, no mesmo quarto de pensão em que se iniciou, já chegada a madrugada e a hora de caçar os patos. O tempo do discurso, não ultrapassa portanto, a duração fixada pela medida trágica aristotélica: vinte e quatro horas. São as digressões que determinam a extensão do tempo do discurso.

O tempo da instância narrativa mantém estreitas relações com os outros dois tempos do romance. Ele se manifesta cada vez que o narrador estabelece tais relaçōes em uma ordem singular, a parti: de si mesmo para com a obra composta.

Esta espécie de tempo em a'guns casos se confunde com o tempo da ação e mesmo com o tempo do discurso. E o caso do início do romance: "Cá estou. Precisamente no mesmo quario onde, faz hoje um ano me instalei na minha primeira visita à aldeia e onde, com divertimento e curiosidade, fui anotondo as minhas conversas com Tomás Manuel da Palma Bravo, o Engenheiro". (p. 9)

Sente-se, neste trecho, o estabelecimento do tempo da ação, quando o narrador menciona a primeira visita à Gafeira, experiência alimentadora das analepses ou flashes-back, do tempo do discurso pelo início "in ultima re" e do tempo da instância narrativa pelo envolvimento do narrador na marcação temporal.

No cap. 2, temos um exemplo do tempo da instância narrativa, que trata do processamento temporal da escrita do romance. Naquela passagem, o narrador sublinha a diferença entre o tempo da ação e o do discu:so, estabelecendo, nas observaçōes, o terceiro tempo, exatamente aquele de que tratamos aqui. Depois de uma curta desciç̧ão onde figuram o casal Palma Bravo e a multidão composta de filhas de Maria e viúvas-de-vivos, O narrador comenta: "S $\delta$ que me demorei demasiado com coisas à margem, fantasmas, questões de café - e, com audo isto o nosso homem já está ao volante do carro". (p. 34)

Na passagem acima o na:rador afirma a sua impotência para controlar o tempo, como se a ação narrada tivesse o mesmo desenvolvimento da ação vivida, onde o tempo não para. Teoricamente o narrador é soberano no processamento temporal da narrativa, mas a experiência literária rela:ada tem demonstrado que o narrador, a partir de um determinado momento da na:rativa, deixa de conduzí- 
- la para ser conduzido por ela. A dinâmica da ação supera a da narração e o lapso de ação que deixa de ser narrado é a coordenada que submete $o$ narrador ao ato de narrar.

O tratamento dado ao tempo na segmentação da narrativa (capítulos) é bem definido. Todos os capítulos se iniciam no presente "atual", isto é na segunda visita do narrador à Gafeira, com exceção do capítulo 30 , que começa com a evocação da morie do criado em que se cruzam observaçōes dos habitantes da Gafeira. No entan10, tudo se passa como produlo do estado de vigília do narrador, cuja memória, exaurida pelas emoções vividas nas últimas horas, perde-se no emaranhado de impressões distantes e recentes. Deste modo, até mesmo esse capítulo se refere explicitamente ao presente da narração, dissimulado por lembranças caóticas.

Os capítulos, como afirmamos, iniciam-se sempre no presente e pouco a pouco vão deslizando para o passado; os dois tempos muitas vezes coexisiem por alguns momentos em imagens superpostas, algumas delas obedecendo à estrutura especular, como se analisa em outra parte deste trabalho. Do final de um capitulo para - início de outro, nota-se um esforço de despojamento da memoria e da fantasia para que seja possível a retomada objetiva dos fatos. Esforço inútil, pois em todos os capítulos, o discurso, por força de associações mnemônicas, acaba se voltando para o passado.

Cada capítulo é, portanto, o começo reencetado, uma nova "mise-en-scène" do mesmo drama. A repetição levemente alterada das situações, introduz uma nova dimensão na rede temporal. Há casos em que o episódio relatado em um capítulo é "corrigido" por outro (cf. os capítu'os dos lenços vermelhos das amantes do Gado e do Crime das Unhas de Pra:a, este último resgatado pela memória).

Esta repetição corretiva atua como um silogismo dialérico, isto $\epsilon$, afirma as duas versões como prováveis, delas se extraindo uma terceira, a do leitor.

A determinação da temporalidade é conseguida por recursos estilísticos que passamos a enumerar:

1) Datação - é a necessidade imperiosa de inscrever o relato em um tempo maior - o tempo histórico: "Desta maneira, o Autor em visita despede-se / . . / na véspera do Dia de Todos os Santos e de todos os caçadores, o primeiro do mês de novembro de mil novecentos e sessenta e seis". (p. 363)

2) Passado recuperado pela memória involuntária (fusão par- 
cial de passado e presente): "Volto-me antes para o largo, e, sem querer, torno à manhã do ano passado em que assisti a aparição do casal Palma Bravo depois da missa". (p. 34)

3) Passado recuperado pela memória voluntária (fusão total de passado e presente): "Puxo pela memória. Estes tipos quanto mais nos olham menos nos querem ver..." (p. 35) Outro exemplo: "Bebe, vou eu a oferecer-lhe, quando repa:o que, fora da caça, nunca ando com o cantil. De resto, se o tivesse trazido também não adiantaria muito. Pelo que tenho bebido esła noite, custa-me a crer que a aguardente ainda chegasse para uma golada a cada um". (p. 296)

Na última passagem citada, verifica-se a fusão perfeita dos tempos. Nota-se que o passado e o presente deixam de ser identificáveis pelo aspecto temporal dos verbos e passam a ser percebidos pelas circunstâncias da descrição. O "bebe" inicial é a continuação de um diálogo entre o narrador e o Engenheiro no outono anterior, e o complemento circunstancial temporal "esta noite" refere-se ao outono atual do discurso. Verifica-se realmente um "deslizamento" do passado para o presente, e deste novamente para $O$ passado. $E$ um movimento pendular que também ocorre no domínio da certeza e da dúvida, redutível à polarização sim e nāo, e que finalmente se reduz à conjunção dos opostos.

4) Inversão dos tempos: o futuro em relação à primeira visita à Gafeira (passado a) tornar-se passado (passado b) em relação à segunda visita (presente). "Admirado pelos jovens de blusão, Tomás Manuel, o Engenheiro, limpa os b́culos escuros com gestos vagarosos. / .../ Obedecerá a certa regra que mais tarde, numa noite ce mau vinho, eu ouviria da boca dele em relação à gente da Gafeira e das suas manhas?" (p. 35)

Além dos recursos assinalados que se realizam a partir de elementos gramático-estilísticos, há o significado cósmico do tempo: a coincidência da visita do närador com a temporada da caça, ao final de outubro, em pleno outono. O narrador cumpre uma função cíclica, comparáve! à da estação da caça. Não se pode desprezar as sugestōes deste iempo específico - o outono. Os aspectos evanescentes e imprecisos da realidade: fumos, nevoeiro, luto, uivo de cães, fantasmas coadunam-se perfeitamente com a estação evocada. Até mesmo as reaçōes e os estados de consciência do narrador são estados "outonă:s". E por que não afirmar também que a sociedade figurada na narrativa é uma sociedade "outonal?" - se o declínio da au:oridade, os depoimentos duvidosos e a confusão labiríntica e o desalento são aspectos de declínio (polo negativo) em 


\section{uma estrutura dada?}

"No mundo divino o processo ou movimento fundamental é o da morte e renascimento, ou o do desaparecimento e retorno ou a da encarnação e reiirada de um deus. Essa. atividade divina identifica-se ou associa-se usualmente com um ou mais de um dos processos cíclicos da natureza. $/ \ldots /^{\prime \prime 1}$

Chamando os quatro elementos narrativos pré-genéricos de mythoi (sing. my:hos) Frye assim os classifica:

1. Mythos da primavera: a comédia

2. Mythos do verão: a estória romanesca

3. Mythos do outono: a tragédia

4. Mythos do inverno: a ironia e a sátira

Não é por acaso que a tragédia aparece na classificação de $\mathrm{N}$. Frye como o mythos do outono (e o autor, nesta questão, mantém-se fiel a Aristóieles). Não discutiremos até que ponto a narrativa de - Delfim é uma narrativa táágica no sentido aristolélico do termo. A tragicidade por nós analisada, e que aliás pode ser sentida em qualquer tipo de leitura que se aplique à obra, é uma tragicidade existencial muito mais do que formal. Isto, porém, não invalida a recorrência ao tipo de classificação p:oposta por Frye, ainda que deixemos de lado a questão da grandeza do heroi trágico e de sua situação supra-humana.

"Na comédia o tempo exerce um papel redentor: descobre e traz à luz o que é essencial para o fim feliz /.../ Mas na tragédia - cognítio é normalmente o reconhecimento da inevitabilidade de uma sequência causal no tempo, e os prenúncios e an'ecipações que a rodeiam fundam-se numa sensação de rtorno cíclico". (op. cit. p. 210)

E aspecto do retorno cíclico que nos atrai a atenção em 0 Delfim; até mesmo a "vo!ta" de Tomás Manuel opera-se no clima mítico sebastiânico (como analisamos no capítulo lconicidade) e coincide com o outono, e a temporada de caça. O narrador volta no outono e com ele, os fatos voltam a ser revividos e a verdade a ser procurada. A caça, é, aliás a grande metáfora da procura, e, ao final, quando o narrador exausto e insone, decide não caçar no dia seguinte é a desistência da busca que ele afirma; ele, porém, a substitui po: outra caçada menos árdua e comprometedora: 
"O que conta é o festim das enguias e logo, a meio da tarde, - arraial dos Noventa e Oito, com tachos de cebo'ada e crepitar ao ar livre, vinho e concertinas. 1550, sim, é que é a caçada de hoje". (p. 362)

Vemos que a caçada a que o narrador se refere é o simples entorpecimento dos sentidos po: meio da comida, vinho e música. Esta "caçada" tem a virtude de anular qualquer exigência me:afísica e de colocar o caçador no estado aleatório do não-pensar, exatamento opost oao estado que deu desenvolvimenio à narrativa.

Concluindo, podemos afirmar que a tempo:alidade de 0 Delfim está intimamente ligjada ao sentido involutivo da nariativa, aquilo que a caracteriza como maneirista e que a inscreve entre as obras em que o discurso tem como limite cronológico a medida dramática aristotélica; são os recursos nariativos que possibilitam que dentro ce um tempo tão breve se instaure um tempo existencial relativamente dilatado, onde se encontram presentes as virtualidades da sonsciência do narrador.

\section{REFERENCIAS BIBLIOGRAFICAS}

PIRES, J. C. O Delfim. 5. ed. Lisboa, Moraes, 1972. 363 p.

${ }^{1}$ FRYE, N. Crítica arquetipica: teoria dos mitos. In:

- Anatomia da crítica. Säo Paulo, Cuitrix, 1973. p. 133-233.

\section{SOMMAIRE}

Cet article, qui fait partie de la thèse "O Deffim, O manoirismo como expressäo do romance contemporâneo", étudie la présentation du temps dans un roman de José Cardoso Pires. Notre étude signale trois manifestations distinctes de la temporalité dons "O Delfim": ie temps de l'action, le temps du discours et le tempsi de l'instance narrative. Après avoir exemplifié ces divers aspects du temps, nous signalons d'autres marques de tempsralité telles que les procédés stylistiques et les a.lusions mythiques du contenu. Pour conclure, nous observons que l'utilisation du temps dans ce roman est, en soi-même, un signe du maniérisme de ce discours narratif. 